\title{
Multiple effects of haemin binding on protease susceptibility of bovine serum albumin and a novel isolation procedure for its large fragment
}

\author{
Weon-Sun SHIN, Honami YAMASHITA and Masaaki HIROSE* \\ The Research Institute for Food Science, Kyoto University, Uji, Kyoto 611, Japan
}

The effects of ligand binding on the proteolytic susceptibility of BSA were investigated. The rate for proteolytic digestion with either trypsin or chymotrypsin decreased in the presence of bilirubin and fatty acids, suggesting that overall albumin conformation is stabilized by these ligands. In contrast, haemin showed multiple effects on a proteolytic digestion pattern: the rate for the degradation of intact albumin greatly increased, but a large $45 \mathrm{kDa}$ fragment accumulated during proteolytic digestion in the presence of this ligand. This unique fragmentation pattern allowed us to isolate the $45 \mathrm{kDa}$ fragment at a high yield (about $30 \%$ on a molar basis) by one-step purification. Sequence analyses indicated that this fragment lies between residues $\mathrm{Thr}^{190}$ and $\mathrm{Ala}^{583}$, which constitutes domains II and III of the albumin molecule. Far-u.v. c.d. spectra strongly suggested that the secondary structure in the intact albumin is almost retained in the $45 \mathrm{kDa}$ fragment. The isolated $45 \mathrm{kDa}$ fragment showed haemin-binding ability, as evaluated by spectroscopic titration; upon re-digestion of the $45 \mathrm{kDa}$ fragment, haemin showed strong protective effects. These results were consistent with the idea that haemin binding to BSA induces an increased protease susceptibility in the loop region between domains I and II, but in the overall conformation of domains II and III, a protease-resistant property.

\section{INTRODUCTION}

Serum albumin is the most abundant plasma protein. It consists of a single chain with a molecular mass of about $66 \mathrm{kDa}$ organized into nine loops stabilized by 17 disulphide bridges (Peters, 1985). Recent X-ray crystallographic data demonstrate that the human serum albumin molecule is composed of three domains, I, II and III, each of which can be further divided into two subdomains, A and B (He and Carter, 1992). This complex multidomain structure allows the albumin molecule great flexibility and conformational adaptability, as seen by its ability to rapidly convert into a number of isomeric forms and to bind a number of ligands, including fatty acids, bilirubin, amino acids, hormones, drugs and metal ions (Peters, 1985). Interestingly, the conformational transition may also be involved in ligand transport to the target cells (Reed and Burrington, 1989).

Because of the large size and complex structure, the use of isolated fragments having native function is important for the detailed analyses of ligand-induced local conformational change in serum albumin. For this reason, extensive studies have been done to isolate functional fragments (Peters, 1985). The fragmentation procedure, however, must include minimal chemical damage, so that highly cross-linked disulphide bonds essential for the native conformation (Lee and Hirose, 1992) remain intact. This has made it difficult to obtain a variety of albumin fragments with intact function: only limited numbers of procedures have been widely accepted, such as proteolytic fragmentation procedures for the two half-molecules (King, 1973; Feldhoff and Peters, 1975; Geisow and Beaven, 1977).

The proteolytic digestion approach has been used as a useful probe for monitoring ligand-induced conformational changes in a large protein (Ueno and Harrington, 1984). The approach is based on an assumption that if the conformational state of a ligand-bound protein is significantly different from the timeaverage conformation in the absence of a ligand, then their products of proteolysis could also be different. Ligand binding usually confers a more resistant conformation upon a globular protein. Thus if a ligand induces a protease-resistant conformation in its binding domain of serum albumin, a variety of functional fragments will be obtained by proteolysis in the presence of various ligands. Typical successful examples of this procedure are the cases of the isolation of the two half-molecules and domain III by proteolysis of fatty acid-bound albumin (King, 1973; Peters and Feldhoff, 1975).

In the present study, we have searched for conditions in which a large fragment of BSA accumulates during proteolysis in the presence of a ligand. Among several tested ligands, haemin showed unique effects on the proteolytic profile of BSA: the digestion rate of the intact molecule was greatly accelerated, but a fragment with a molecular mass of $45 \mathrm{kDa}$, that was assigned to the sequence $\mathrm{Thr}^{190}-\mathrm{Ala}^{583}$, accumulated. The haemin-induced modulation in the protease susceptibility allowed us to isolate a large fragment corresponding to domains II and III in a high yield by one-step purification.

\section{EXPERIMENTAL}

\section{Materials}

Fatty acid-free BSA (type A-7511) was obtained from Sigma Chemical Company. In the present study, we used a so-called 'mercaptalbumin' fraction that was essentially purified as described by Noel and Hunter (1972) except that the DEAEcellulose column was replaced by an f.p.l.c. column (HiRoad XK-26, Pharmacia-LKB Co.). The concentration of BSA was determined using $A_{1 \mathrm{~cm}}^{1 \%} 6.67$ at $279 \mathrm{~nm}$ (Sun and Maximos, 1989). Haemin chloride was a crystalline product from Sigma Chemical Company. It was dissolved at $8.0 \mathrm{mM}$ in $0.01 \mathrm{M} \mathrm{NaOH}$, rapidly diluted with $10 \mathrm{mM}$ Tris $/ \mathrm{HCl}$ buffer, $\mathrm{pH} \mathrm{8.0,} \mathrm{to} \mathrm{a} \mathrm{required}$ concentration, and used in this form within $1 \mathrm{~h}$. The concentration was determined spectrophotometrically using a molar absorption coefficient of $58400 \mathrm{M}^{-1} \cdot \mathrm{cm}^{-1}$ at $385 \mathrm{~nm}$ (Beaven et al., 1974). Chymotrypsin A (EC 3.4.21.1) (type II), trypsin (EC 
3.4.21.4) (diphenylcarbamyl chloride-treated, type XI), bilirubin, and oleic acid were purchased from Sigma Chemical Company. Carboxypeptidase Y (EC 3.4.16.1) was purchased from Oriental Yeast. DEAE-cellulose (DEAE-cellulofine, A-500) was obtained from Seikagaku Kogyo. Other chemicals were guaranteed analytical grade from Nacalai Tesque.

\section{Time course of proteolytic digestion}

BSA or its fragment was digested at $0.5 \mathrm{mg} / \mathrm{ml}$ in $50 \mathrm{mM}$ Tris/ $\mathrm{HCl}$ buffer, $\mathrm{pH} 8.0$, at $37^{\circ} \mathrm{C}$ for various time periods with chymotrypsin or trypsin at a protein to enzyme ratio of $60: 1$ $(w / w)$. To monitor the proteolytic progress, part of the mixture corresponding to $2.6 \mathrm{mg}$ of original BSA was withdrawn and analysed by SDS/PAGE according to the standard method of Laemmli (1970) using a $12.5 \%$ polyacrylamide gel. The gel was stained with Coomassie Blue and band intensities were determined with a densitometer (Shimadzu, CS-9000).

\section{Determination of protease activities with synthetic substrates}

Assays for proteolytic activities using synthetic substrates were essentially carried out as described by Walsh and Wilcox (1970). In brief, $N$-benzoyl-L-tyrosine for chymotrypsin or $p$-toluenesulphonyl-L-arginine methyl ester for trypsin were incubated at $1.0 \mathrm{mM}$ with a protease in $10 \mathrm{mM}$ Tris $/ \mathrm{HCl}$ buffer, $\mathrm{pH} 8.0$, at $37^{\circ} \mathrm{C}$ in the absence or presence of $7.5,15$, or $30 \mathrm{mM}$ haemin. Time-dependent increases in absorption at $247 \mathrm{~nm}$ for trypsin and $256 \mathrm{~nm}$ for chymotrypsin were recorded for $5 \mathrm{~min}$, and activities were calculated from the slope.

\section{Purlfication of $\mathbf{4 5} \mathbf{~ k D a}$ fragment}

BSA was digested at $0.5 \mathrm{mg} / \mathrm{ml}$ with $8.3 \mu \mathrm{g} / \mathrm{ml}$ of chymotrypsin at $37^{\circ} \mathrm{C}$ for $30 \mathrm{~min}$ in $50 \mathrm{mM}$ Tris/ $\mathrm{HCl}$ buffer, $\mathrm{pH} 8.0$, in the presence of $30 \mu \mathrm{M}$ haemin (ligand to protein molar ratio of $4: 1$ ). Proteolysis was terminated by the addition of 0.01 vol. of $50 \mathrm{mM}$ phenylmethanesulphonyl fluoride, and the $\mathrm{pH}$ of the mixture was adjusted to 3.0 by the addition of $0.1 \mathrm{M} \mathrm{HCl}$. Haemin was removed from the mixture by treatment with 1 vol. of watersaturated n-butanol, then the $\mathrm{pH}$ of the mixture was raised up to 8.0 with $0.1 \mathrm{M}$ Tris base. The chymotrypsin digests were loaded on to a DEAE-cellulose column $(1.0 \mathrm{~cm} \times 7.0 \mathrm{~cm})$ equilibrated with $10 \mathrm{mM}$ Tris/ $\mathrm{HCl}$ buffer, $\mathrm{pH} 8.0$, and eluted with an $80 \mathrm{ml}$ linear gradient (10-500 $\mathrm{mM})$ of the same buffer. The temperature was kept at $4{ }^{\circ} \mathrm{C}$ during the isolation procedure. Eluted protein fragments were analysed by SDS/PAGE in the same way as described above. Peak fractions containing a $45 \mathrm{kDa}$ fragment were collected, dialysed against distilled water, concentrated with a Centricon-10 ultrafilter (Amicon), and used for further analyses. The absorption coefficient of the $45 \mathrm{kDa}$ fragment was determined as described by Gill and von Hippel (1989).

\section{N- and C-torminal sequence analyses}

The $\mathrm{N}$-terminal amino acid sequence of the $45 \mathrm{kDa}$ fragment was determined with a protein sequenator (Applied Biosystems model 477A/120A). The C-terminal amino acid sequence was determined by sequential digestion with carboxypeptidase $Y$. The $45 \mathrm{kDa}$ fragment, or intact BSA as a control, was denatured by incubation in $20 \mathrm{mM} \mathrm{N}$-ethylenemorphyrine buffer, $\mathrm{pH} \mathrm{7.0,}$ containing $8 \mathrm{M}$ urea at $30^{\circ} \mathrm{C}$ for $10 \mathrm{~min}$. The sample was diluted with 1 vol. of the same buffer and incubated at $30^{\circ} \mathrm{C}$ for various times with carboxypeptidase $Y$ at a protein to enzyme molar ratio of 50:1. Aliquots of the digestion sample were withdrawn and mixed with 0.1 vol. of $6 \mathrm{M} \mathrm{HCl}$, and then diluted with 2.47 vol. of $0.2 \mathrm{M}$ sodium citrate buffer, $\mathrm{pH} 2.2$. Released amino acids were quantified with an amino acid analyser (Hitachi amino acid analyser, Type-835).

\section{Measurement of c.d. spectra}

The far-u.v. c.d. spectra of intact BSA and the $45 \mathrm{kDa}$ fragment were measured at $0.1 \mathrm{mg} / \mathrm{ml}$, using a cuvette of $0.1-\mathrm{cm}$ light path, in $50 \mathrm{mM}$ Tris $/ \mathrm{HCl}$ buffer, $\mathrm{pH} 8.0$, at room temperature with a spectropolarimeter (Jasco J-720). The data were expressed as mean residue ellipticity (degree $\cdot \mathrm{cm}^{2} \cdot \mathrm{dmol}^{-1}$ ), using the mean residue weights of 113.9 for the intact molecule, and 113.3 for the $45 \mathrm{kDa}$ fragment.

\section{Spectrophotometric titration with haemin}

The solution containing $6.6 \mathrm{mM}$ of intact BSA or of the $45 \mathrm{kDa}$ fragment was titrated with haemin in $50 \mathrm{mM}$ Tris/ $\mathrm{HCl}$ buffer, pH 8.0. The reference mixture containing the same buffer was titrated in the same way', and differences in absorbance at $410 \mathrm{~nm}$ were recorded at $37^{\circ} \mathrm{C}$ with a u.v.-visible recording spectrophotometer (Shimadzu, UV-260) as described by Beaven et al. (1974).

\section{RESULTS}

\section{Effects of ligands on proteolytic digestion rates}

BSA was digested at $0.5 \mathrm{mg} / \mathrm{ml}$ with trypsin or chymotrypsin in the presence or absence of a ligand, and the time course of digestion was monitored by SDS/PAGE. A previous report demonstrates that the $K_{\mathrm{m}}$ value (Michaelis constant) of the enzyme is $11.0 \mathrm{mg} / \mathrm{ml}$ for serum albumin (Markus et al., 1967), indicating that the proteolysis should proceed via pseudo-firstorder kinetics at an employed substrate concentration as low as $0.5 \mathrm{mg} / \mathrm{ml}$. Thus the rate for proteolysis was determined from the slope in the semi-logarithmic plots of the amount of intact albumin versus digestion time.

As summarized in Table 1, the rate for proteolytic digestion greatly decreased in the presence of bilirubin or oleic acid at a

\section{Table 1 Effects of ligands on the rates for proteolytic digestion of serum} albumin

BSA was digested with chymotrypsin or trypsin for various times in the presence or absence of a ligand and electrophoresed on a polyacrylamide gel as described in the text. The band intensities of intact BSA were determined with a densitometer. Pseudo-first-order rate constants for the proteolytic digestion were determined from the slope of the semi-logarithmic plots of intact BSA versus digestion time. Relative rate constants were calculated as the rate in the absence of a ligand taken as 1.0. The data are the averages for four determinations ( \pm S.E.M.). N.D. represents 'data not determined'.

\begin{tabular}{llll}
\hline & & \multicolumn{2}{l}{ Relative rate constant } \\
\cline { 3 - 4 } Ligand & $\begin{array}{l}\text { Molar ratio } \\
\text { (ligand:albumin) }\end{array}$ & Chymotrypsin & Trypsin \\
\hline Bilirubin & 1.0 & $0.11 \pm 0.04$ & $0.34 \pm 0.04$ \\
Oleic acid & 1.0 & $0.66 \pm 0.08$ & $0.68 \pm 0.05$ \\
Linoleic acid & 1.0 & $0.40 \pm 0.03$ & $0.68 \pm 0.05$ \\
& 2.0 & $0.11 \pm 0.01$ & N.D. \\
Haemin & 4.0 & $0.02 \pm 0.01$ & N.D. \\
& 1.0 & $1.88 \pm 0.30$ & $2.90 \pm 0.50$ \\
& 2.0 & N.D. & $6.12 \pm 1.18$ \\
& 4.0 & N.D. & $12.06 \pm 0.42$ \\
\end{tabular}



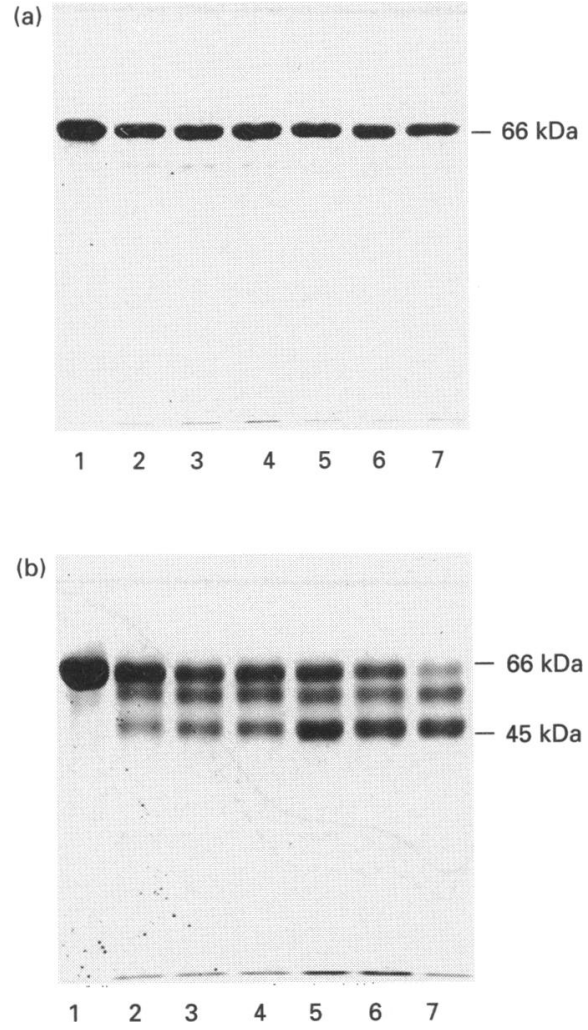

Figure 1 Effects of haemin on the fragmentation pattern of BSA

BSA was digested with chymotrypsin in the absence (a) or presence (b) of haemin at a ligand to albumin molar ratio of 4:1 for $0 \mathrm{~min}$ (lane 1), $5 \mathrm{~min}$ (lane 2), $10 \mathrm{~min}$ (lane 3), $15 \mathrm{~min}$ (lane 4), $30 \mathrm{~min}$ (lane 5), $45 \mathrm{~min}$ (lane 6), or $60 \mathrm{~min}$ (lane 7). The samples corresponding to $2.6 \mu \mathrm{g}$ of original BSA were analysed by SDS/PAGE as described in the text.

ligand to albumin molar ratio of $1: 1$, and the extent of chymotrypsin inhibition was increased with increasing molar ratio of linoleic acid. In contrast, haemin increased the rate for the proteolytic digestion with increasing molar ratios of ligand to albumin. We confirmed that the increased digestion should not be accounted for by an activation of protease activity, since the proteolytic activities for the synthetic substrates of $N$-benzoyl-Ltyrosine for chymotrypsin and $p$-toluenesulphonyl-L-arginine methyl ester for trypsin were not affected by the same concentrations of haemin (results not shown). In addition, no BSA proteolysis by haemin was detected in the absence of an added protease (results not shown). Thus we concluded that the increased proteolysis rate by haemin can be accounted for by an alteration in the protease susceptibility of BSA.

\section{Accumulation of the $\mathbf{4 5} \mathrm{kDa}$ fragment}

The preceding proteolysis data were determined as degradation rates of intact albumin. Figure 1, however, demonstrates that a $45 \mathrm{kDa}$ fragment accumulated during chymotrypsin digestion in the presence of haemin. We quantitatively analysed the extent of accumulation of the $45 \mathrm{kDa}$ fragment at various molar ratios of haemin to BSA. Figure 2 shows that the accumulation of the fragment was much greater in the presence of haemin than in the absence of the ligand. At a haemin to BSA molar ratio of $4: 1$ and

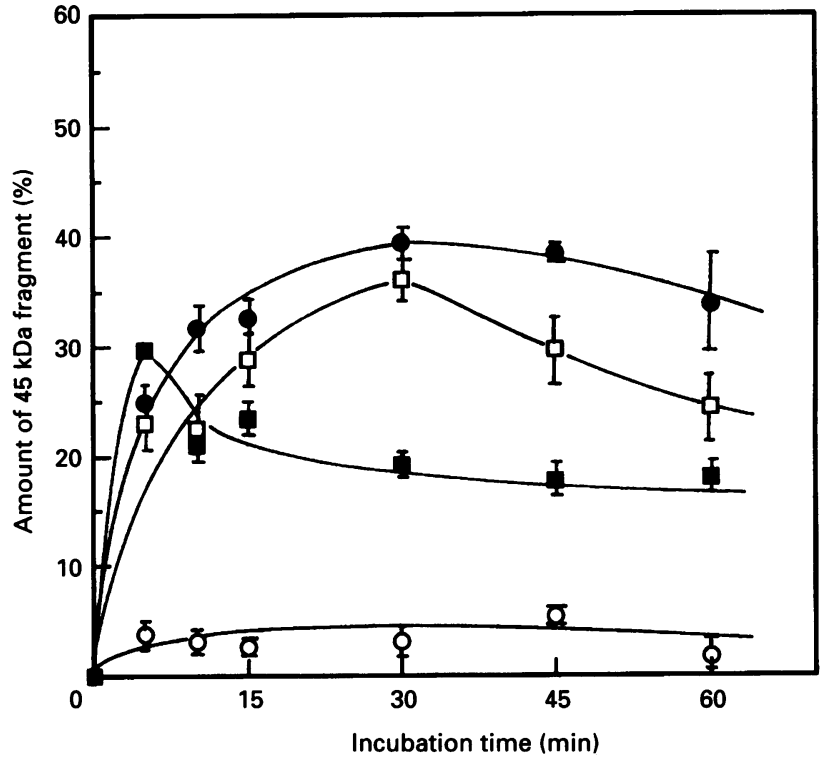

Figure 2 Quantitative analyses for the accumulation of a $\mathbf{4 5} \mathrm{kDa}$ fragment

BSA was digested with chymotrypsin for various times in the absence $(O)$, or the presence of haemin at a ligand to protein ratio of $1: 1(\square), 2: 1(\square)$, or $4: 1(\bigcirc)$. The samples, corresponding to $2.6 \mu \mathrm{g}$ of original BSA, were analysed by SDS/PAGE and the band intensities for the $45 \mathrm{kDa}$ fragment were determined with a densitometer. The ordinate represents the percentage of the band intensity of the $45 \mathrm{kDa}$ fragment compared with the intensity of intact BSA at incubation time zero. Data are the averages of duplicate determinations.

30 min digestion, the amount of fragment was almost $40 \%$ of the original intact form. Essentially the same accumulation of the $45 \mathrm{kDa}$ fragment in the presence of haemin was also observed for trypsin digestion (data not shown). Thus the results in Figure 2, along with those in Table 1, strongly suggest that haemin has at least two types of effects on the protease susceptibility of BSA, thereby facilitating the degradation of the intact form but protecting the $45 \mathrm{kDa}$ fragment that is an early degradation product of the intact form.

\section{Purlfication of the $\mathbf{4 5} \mathbf{~ k D a}$ fragment}

To assign the $\mathrm{N}$-terminal amino acid sequence of the $45 \mathrm{kDa}$ fragment, BSA was digested with trypsin or chymotrypsin in the presence of haemin (ligand to albumin molar ratio $4: 1$ ), electrophoresed on a polyacrylamide gel and then electroblotted on to a poly(vinylidene difluoride) membrane. The band corresponding

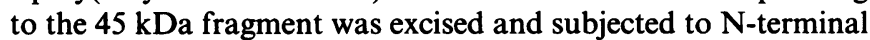
sequence analysis. Data showed that the tryptic $45 \mathrm{kDa}$ fragment consisted of two N-terminal amino acid sequences: one is GlnArg-Leu-Arg- and the other, Leu-Arg-Xaa-Ala-. In contrast, chymotrypsin generated a single $\mathrm{N}$-terminal sequence: $\mathrm{Thr}-\mathrm{Ser}-$ Ser-Ala-Arg-. From these results, the $\mathrm{N}$-terminal amino acid of the chymotryptic fragment can be assigned according to the established primary sequence of BSA (Brown, 1975; Reed et al., 1980; Hirayama et al., 1990) as $\mathrm{Thr}^{100}$, and those of the tryptic fragments, as $\mathrm{Gln}^{195}$ and $\mathrm{Leu}^{197}$, strongly suggesting that the loop region between the first and second domains was made more susceptible by haemin to either trypsin or chymotrypsin.

To isolate a $45 \mathrm{kDa}$ fragment having a single $\mathrm{N}$-terminal sequence, we employed proteolytic conditions using chymotrypsin. BSA $(17 \mathrm{mg})$ was digested at $0.5 \mathrm{mg} / \mathrm{ml}$ with chymotrypsin in the presence of haemin at a ligand to albumin ratio of 


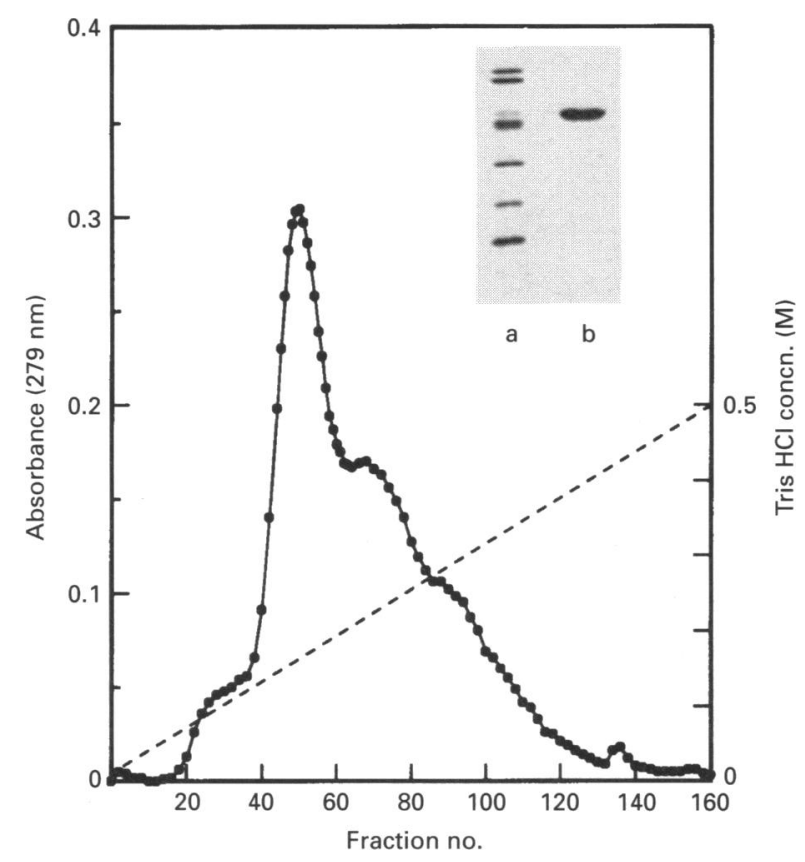

Figure 3 Elution profile of chymotrypsin digests from a DEAE-cellulose column

BSA $(17 \mathrm{mg})$ was digested at $37^{\circ} \mathrm{C}$ for 30 min with chymotrypsin in the presence of haemin (ligand to protein molar ratio 4:1). The sample was loaded on to a DEAE-cellulose column and eluted with a linear gradient $(--)$ of Tris/HCl buffer, $\mathrm{pH} 8.0(10-500 \mathrm{mM})$ as described in the text. The absorbance ( ) of each fraction $(0.5 \mathrm{ml})$ was determined at $279 \mathrm{~nm}$, and peak fractions (fractions 40 to 58 ) that corresponded to the $45 \mathrm{kDa}$ fragment were collected, dialysed against distilled water, and concentrated with a Centricon-10 (Amicon) to about $1.7 \mathrm{mg} / \mathrm{ml}$. In the inset, this purified $45 \mathrm{kDa}$ fragment in lane $\mathrm{b}$ and a mixture consisting of standard proteins (fructose-6-phosphatase, $85.2 \mathrm{kDa}$; BSA, $66.2 \mathrm{kDa}$; aldolase, $39.2 \mathrm{kDa}$; triosephosphate isomerase, $26.6 \mathrm{kDa}$; soybean trypsin inhibitor, $21.5 \mathrm{kDa}$; lysozyme, $14.4 \mathrm{kDa}$ ) in lane a were analysed by SDS/PAGE as described in the text.

4:1 for $30 \mathrm{~min}$. The digest was applied to an ion-exchange column and eluted as shown in Figure 3. SDS/PAGE analyses for the fractions revealed that the major peak contained the $45 \mathrm{kDa}$ fragment. Peak fractions were collected, dialysed against distilled water, and concentrated. On SDS/PAGE, the sample showed a single band (Figure 3, inset). From $17 \mathrm{mg}$ of original BSA (mercaptalbumin), $3.43 \mathrm{mg}$ of the purified fragment was obtained. Thus the recovery was $29.6 \%$ on a molar basis.

The value for $A_{1 \mathrm{~cm}}^{1^{\circ} \mathrm{o}}$ at $280 \mathrm{~nm}$ of the $45 \mathrm{kDa}$ fragment determined by the method of Gill and von Hippel (1989) was 4.98. The concentration of the $45 \mathrm{kDa}$ fragment was determined spectrophotometrically on the basis of this value.

\section{$\mathrm{N}$ - and $\mathbf{C}$-terminal sequence analyses of the isolated fragment}

To assign more exactly the primary structure, we determined the $\mathrm{N}$ - and C-terminal sequences of the isolated chymotrypsin fragment. The $\mathrm{N}$-terminal amino acid sequence, determined with a protein sequenator, was again Thr-Ser-Ser-Ala-Arg-, indicating that the $\mathrm{N}$-terminal amino acid of the fragment corresponds to $\mathrm{Thr}^{190}$ in intact BSA.

We determined the C-terminal amino acid sequence of the $45 \mathrm{kDa}$ chymotrypsin fragment in such a way that the time course for the digestion with carboxypeptidase $\mathrm{Y}$ is compared

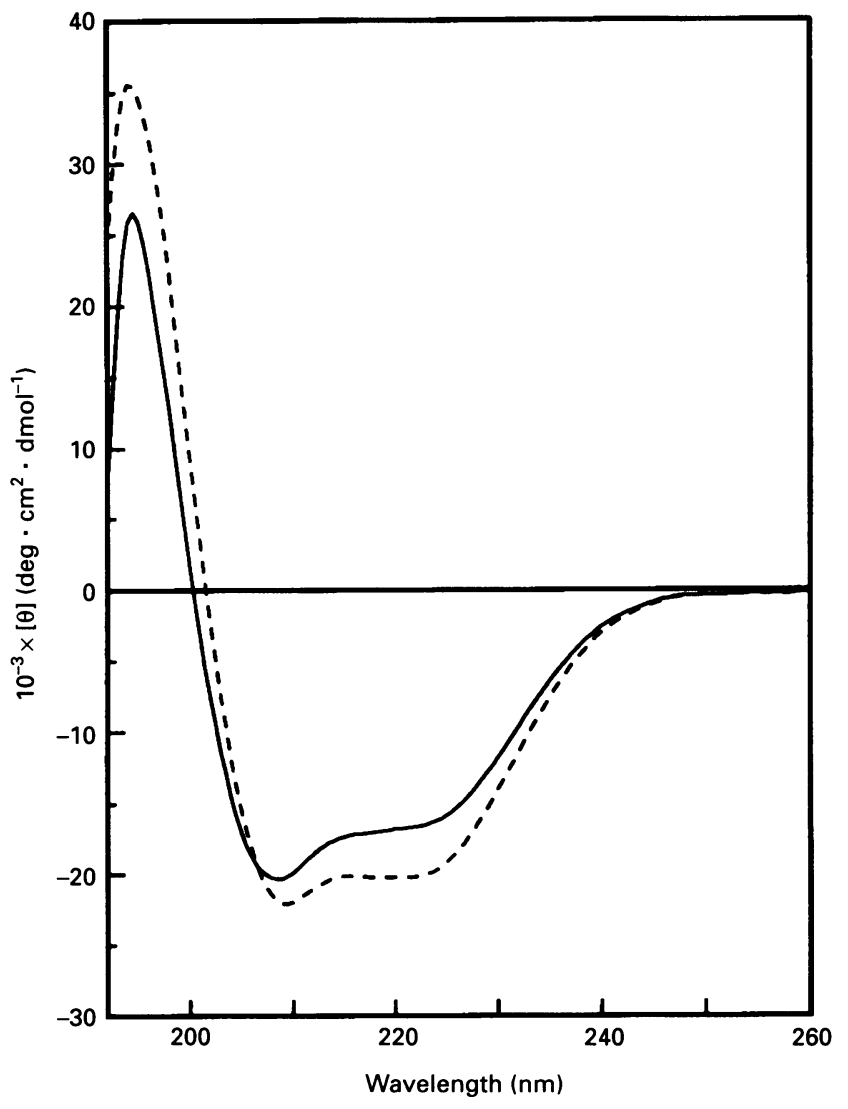

Figure 4 Far-u.v. c.d. spectra

The far-u.v. c.d. spectra of intact BSA (broken line) and the $45 \mathrm{kDa}$ fragment (solid line) were measured as described in the text. The data, the averages of duplicate determinations, were expressed as mean residue ellipticity (degree $\cdot \mathrm{cm}^{2} \cdot \mathrm{dmol}^{-1}$ ).

between the fragment and intact BSA. The time course for the amino acid release from intact albumin was consistent with the established C-terminal sequence (-Ser-Thr-Gln-Thr-Ala-LeuAla): alanine and leucine were, respectively, the first and second amino acids released. The release of threonine plus glutamine was followed, and then a slow release of serine was observed. This profile was essentially the same as the time course of amino acid release from the $45 \mathrm{kDa}$ fragment. Thus, we concluded that the C-terminal amino acid sequence of the chymotryptic $45 \mathrm{kDa}$ fragment is the same as that of intact BSA.

From the $\mathrm{N}$ - and $\mathrm{C}$-terminal sequence data, the $45 \mathrm{kDa}$ fragment was assigned to the sequence of $\mathrm{Thr}^{190}$ to $\mathrm{Ala}^{583}$, which corresponds to domains II and III of BSA.

\section{C.d. spectra}

To obtain conformational information about the purified $45 \mathrm{kDa}$ fragment, we compared the far-u.v. c.d. spectra of this fragment with that of intact BSA. As shown in Figure 4, the spectrum of intact BSA showed two minima at $209 \mathrm{~nm}$ and $222 \mathrm{~nm}$. This profile was essentially the same as previous data for intact BSA (Sun and Maximos, 1989). The c.d. spectrum of the $45 \mathrm{kDa}$ fragment was very similar to that of intact BSA, although the absolute intensity of the fragment was slightly decreased compared with that of intact BSA (Figure 4). Previous X-ray crystallographic analyses have demonstrated that serum albumin comprises three homologous structural domains, I, II and III 


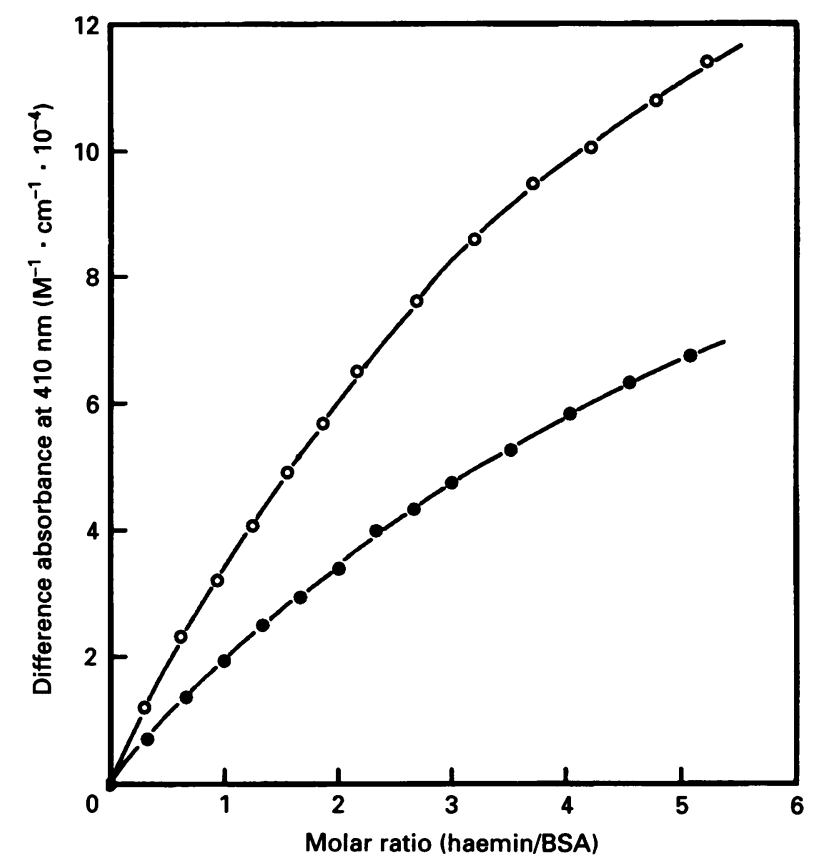

Figure 5 Spectroscopic titration with haemin

Intact BSA $(O)$ or the isolated $45 \mathrm{kDa}$ fragment $(O)$ was titrated with haemin, and difference molar absorption at $410 \mathrm{~nm}$ was plotted versus the ligand to protein molar ratios. Data are the averages of duplicate determinations.

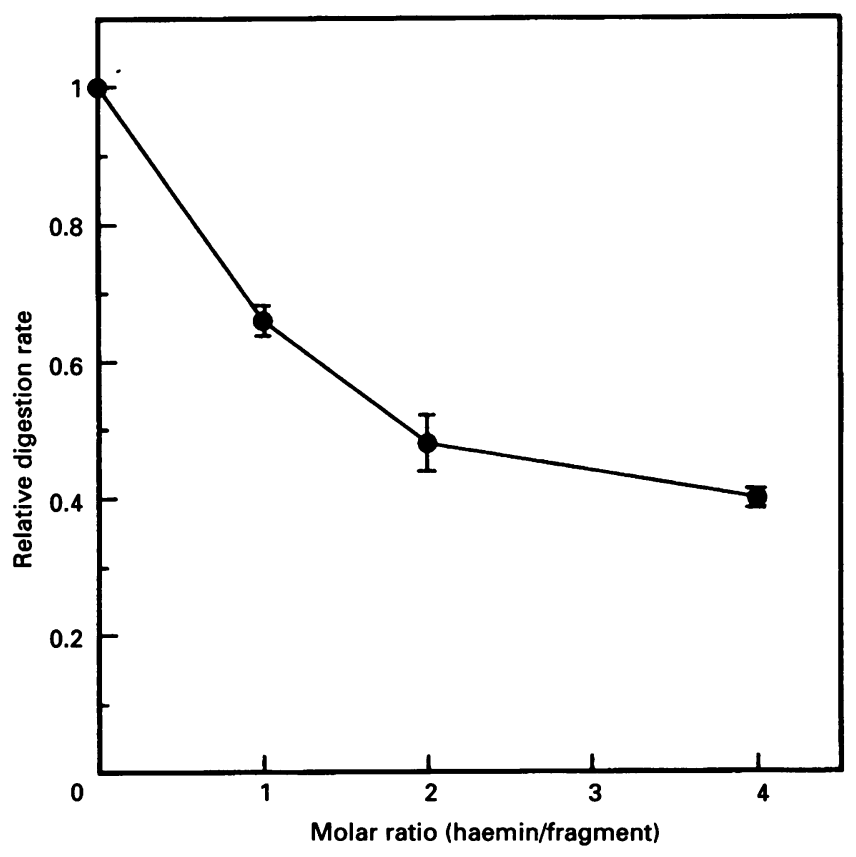

Figure 6 Protection by haemin of the $\mathbf{4 5} \mathrm{kDa}$ fragment from proteolytic digestion

The isolated $45 \mathrm{kDa}$ fragment was digested at $37^{\circ} \mathrm{C}$ for various times with chymotrypsin in the presence of haemin at different molar ratios to albumin, and analysed by SDS/PAGE as described in the text. The band intensities for the $45 \mathrm{kDa}$ fragment were determined with a densitometer and the rates for digestion were calculated by the semi-logarithmic plots of the band intensities versus incubation time as described in Table 1. Relative rates to a control (the rate in the absence of the ligand) are shown in the ordinate. Data are the averages of duplicate determinations.
(He and Carter, 1992). It is therefore very likely that the fragmentation by chymotrypsin induces no drastic alteration in the conformation of domains II and III of BSA.

\section{Spectrophotometric titration with haemin}

The difference u.v. spectrum in the Soret region showed a maximum at $410 \mathrm{~nm}$ with either the $45 \mathrm{kDa}$ fragment or intact BSA (results not shown). Thus spectroscopic titration with haemin was carried out at $410 \mathrm{~nm}$. As shown in Figure 5, in the titration of intact albumin the difference absorbance gradually increased with increasing molar ratios of ligand to protein, but there was no defined end-point. This titration profile was very similar to the previous one for intact human serum albumin, in which there is one strong binding site and several weaker binding sites for haemin (Beaven et al., 1974). The titration profile of the $45 \mathrm{kDa}$ fragment was similar to that of intact albumin in terms of the absence of any sharp end-point, but the difference absorption intensity was much lower in the fragment than in the intact protein. These results suggested that only weak binding sites are included in the $45 \mathrm{kDa}$ fragment.

\section{Effects of haemin on the digestion rate of the isolated $45 \mathrm{kDa}$ fragment}

To investigate the effects of haemin on the proteolytic susceptibility of domains II and III, the isolated $45 \mathrm{kDa}$ fragment was digested with chymotrypsin in the presence of haemin at various molar ratios of ligand to protein. Figure 6 shows that the rate for digestion of the $45 \mathrm{kDa}$ fragment was markedly decreased with increasing haemin to albumin molar ratios, indicating that haemin induces some protease-resistant conformation in the $45 \mathrm{kDa}$ fragment.

\section{DISCUSSION}

In an early study, haemin transfer from globin to albumin was found to be species specific, and did not occur with many animal albumins other than primate proteins (Liang, 1957). On the basis of this observation, most studies of haemin bindings have been done with human serum albumin. In the present study, however, we have found that haemin has multiple effects on the proteolytic digestion of BSA: in the presence of this ligand, the rate of degradation of intact BSA with either trypsin or chymotrypsin increased; but a large $45 \mathrm{kDa}$ fragment consisting of domains II and III ( $\mathrm{Thr}^{190}-\mathrm{Ala}^{583}$ ) accumulated (Table 1 and Figures 1 and 2). These effects should not be accounted for by changes in enzymic activity but by conformational changes in the substrate molecule due to binding of the ligand, since either trypsin or chymotrypsin activity, when assayed using a synthetic substrate, was not affected by haemin. More directly, the spectroscopic titration data (Figure 5) demonstrate that haemin binding does occur in BSA. Binding of haemin to BSA has also been shown in previous spectroscopic studies by Marden et al. (1989).

The present study provides some information about the mode of haemin binding in intact BSA. Previous studies have shown that human serum albumin has one high-affinity binding site and additional low-affinity sites for haemin (Beaven et al., 1974). The acceleration of the degradation rate of intact albumin can be observed at a haemin to protein molar ratio of $1: 1$ (Table 1); the $\mathrm{N}$-terminal amino acid of the large fragment generated by proteolysis is $\mathrm{Thr}^{190}$ with chymotrypsin, or $\mathrm{Gln}^{195}$ and $\mathrm{Leu}^{197}$ with trypsin. A previous report has shown that haemin binds to a cyanogen bromide fragment, $M$ (residues 124-298), with a higher affinity than to fragment $N(1-123)$ or $C(299-585)$ of 
human serum albumin (Hrkal et al., 1978). These results strongly suggest that the primary high-affinity binding occurs in the proximity of the loop between the first and the second domain, thereby inducing some accessible conformation against a protease. The spectroscopic titration profile indicates the occurrence of haemin binding in the isolated large fragment with a lower affinity than in the intact form (Figure 5); but the haemin binding protects the fragment from proteolysis (Figure 6). Thus it is very likely that haemin binds to secondary weak binding sites in domain(s) II and/or III, thereby protecting the fragment from proteolysis.

This unique fragmentation profile allowed us to isolate the $45 \mathrm{kDa}$ fragment in a high yield by one-step purification. Previous studies have shown that a similar large fragment consisting of domains II and III can be produced by limited trypsinization of bovine (King and Spencer, 1970; Peters and Feldhoff, 1975) and human (Bos et al., 1988) serum albumin in the absence of a ligand. Trypsin, however, generates heterogeneous $\mathrm{N}$-terminal amino acids, such as Leu, Thr, Val and Tyr (Peters and Feldhoff, 1975), as also observed in trypsinization in the presence of haemin in the present study $\left(\mathrm{Gln}^{195}\right.$ and $\left.\mathrm{Leu}^{197}\right)$. In contrast, chymotrypsin digestion in the presence of haemin, as employed in the present study, gives a single $\mathrm{N}$-terminal amino acid and reproducibly high yield (about $30 \%$ on a molar basis) of the fragment.

In conclusion, isolation procedures for albumin fragments having the native conformation and function are very important for studies of $\mathrm{pH}$-dependent multiple conformational transitions and of the localization of ligand-binding sites in serum albumin. Although mercaptalbumin was used for the proteolytic fragmentation in the present paper, we have observed that the same chymotryptic $45 \mathrm{kDa}$ fragment can be obtained from nonfractionated fatty acid-free BSA at a high yield (W.-S. Shin and M. Hirose, unpublished work). Partial chymotrypsinization of
BSA in the presence of haemin, therefore, appears to be a useful procedure for the isolation of a large fragment consisting of domains II and III.

This work was supported in part by a grant-in-aid for scientific research from the Ministry of Education, Science and Culture of Japan and by the Ryoichi Naito Foundation for Medical Research.

\section{REFERENCES}

Beaven, G. H., Chen, S. H., d'Albis, A. and Gratzer, W. B. (1974) Eur. J. Biochem. 41 $539-546$

Bos, O. J. M., Fischer, M. J. E., Wilting, J. and Janssen, L. H. M. (1988) Biochim. Biophys. Acta $953,37-47$

Brown, J. R. (1975) Fed. Proc. Fed. Am. Soc. Exp. Biol. 34, 591

Feldhoff, R. C. and Peters, T., Jr. (1975) Biochemistry 14, 4508-4514

Geisow, M. J. and Beaven, G. H. (1977) Biochem. J. 161, 619-625

Gill, S. C. and von Hippel, P. H. (1989) Anal. Biochem. 182, 319-326

He, X. M. and Carter, D. C. (1992) Nature (London) 358, 209-215

Hirayama, K., Akashi, S., Furuya, M. and Fukuhara, K. (1990) Biochem. Biophys. Res. Commun. 173, 639-646

Hrkal, Z., Kodicek, M., Vodrazka, Z., Meloun, B. and Moravek, L. (1978) Int. J. Biochem. 9, 349-355

King, T. P. (1973) Arch. Biochem. Biophys. 156, 509-520

King, T. P. and Spencer, M. (1970) J. Biol. Chem. 245, 6134-6148

Laemmli, U.K. (1970) Nature (London) 227, 680-685

Lee, J. Y. and Hirose, M. (1992) J. Biol. Chem. 267, 14753-14758

Liang, C.-C. (1957) Biochem. J. 66, 552-558

Marden, M. C., Hazard, E. S., Leclerc, L. and Gibson, Q. H. (1989) Biochemistry 28, 4422-4426

Markus, G., McClintock, D. K. and Castellani, B. A. (1967) J. Biol. Chem. 242, 4402-4408

Noel, J. K. F. and Hunter, M. J. (1972) J. Biol. Chem. 247, 7391-7406

Peters, T., Jr. (1985) Adv. Protein Chem. 37, 161-245

Peters, T., Jr. and Feldhoff, R. C. (1975) Biochemistry 14, 3384-3391

Reed, R. G. and Burrington, C. M. (1989) J. Biol. Chem. 264, 9867-9872

Reed, R. G., Putnam, R. W. and Peters, T., Jr. (1980) Biochem. J. 191, 867-868

Sun, S. F. and Maximos, A. S. (1989) Int. J. Pept. Protein Res. 34, 46-51

Ueno, H. and Harrington, W. F. (1984) J. Mol. Biol. 173, 35-61

Walsh, K. A. and Wilcox, P. E. (1970) Methods Enzymol. 19, 31-63 